\title{
What is fundamental for the maintenance of excellence in scientific periodicals?
}

\author{
Richard K. Parrish II
}

$\mathrm{I}^{2}$ am honored to contribute to this centenary edition of what will mark a landmark in the publication of medical science for the Revista de Medicina from the University of Sao Paulo Medical School. In response to the question, "What is fundamental for the maintenance of excellence in scientific periodicals?", as an author, clinician scientist, and the Editor in Chief of the American Journal of Ophthalmology, my answer has remained the same. The criteria for meaningful scientific contributions in clinical medicine are threefold:

First, is the information true? Is the methodology sufficiently rigorous to support the conclusions? Do the authors adequately disclose the potential biases and limitations of their findings? Could another investigator repeat the study based on the information provided and test the hypothesis in an identical manner?

Secondly, is the information new? Do the findings generate novel ideas or test recently proposed findings or hypotheses of other investigators? Is this just another "me, too" article that provides no additional perspective?
Thirdly, does the information either provide either insight into the pathogenesis of a condition or improve our diagnostic ability or affect treatment decisions or allow us to assess our intervention outcomes more meaningfully.

If the author can honestly answer "yes" to these questions, then the likelihood of publication and making a meaningful contribution is very high. Having accurate and novel information is not alone sufficient if members of the intended audience are physicians with primary clinical interests. Fortunately the medical literature community is blessed with many avenues for the publication of basic scientific findings that may one day yield new treatments and better outcomes. It is the responsibility of the editorial board members to weigh carefully those findings that are most likely to help us provide better patient care in the future.

Congratulations on your anniversary and best wishes for the next 100 years.

\footnotetext{
Associate Dean for Graduate Medical Education, University of Miami School of Medicine. Edward W.D. Norton, M. D. Chair in Ophthalmology. Professor of Ophthalmology and Director of Glaucoma Service of Bascom Palmer Eye Institute. Editor-in-Chief American Journal of Ophthalmology.
} 